\title{
Research on the Flipped Teaching Mode in College English Micro Course
}

\author{
Cheng Zhang \\ Jiang Xi Police Institute, Jiang Xi, Nan Chang, 330000, China
}

Keywords: College English; micro teaching; flipped classroom; Mooc.

\begin{abstract}
In recent years, the teaching research and reform practice have been the hot spots on the information education reform. Under the new situation of "Internet+ Education", the huge change in the mobile internet and the opening teaching mood has unprecedented development. All educational concepts are tending to kinds of micro feature mood in our surroundings. The creative teaching moods such as "Micro teaching, Mooc, Flipped classroom" has reached into many schools. So, how to deeply integrate micro teaching with flipped classroom? How to set up creative teaching situation and push forward to the practice and application in college micro teaching. These are the key points on this paper. And it not only compares the concepts of these three modes, but also analyzes their respective characteristics. Also, the relationship between the three is also discussed.
\end{abstract}

\section{Introduction}

\subsection{Research on the literature review at abroad:}

In the fall of 2008, the word "Micro lecture" was firstly proposed by David Penrose, the San Juan College in New Mexico, USA, who is known as the One Minute Professor. And He has referred the course as "knowledge burst ". One Minute Professor ", as its name implies, refers to the teaching of knowledge within a minute. The core idea is to ask the teacher to associate the teaching content with the teaching goal tightly. It produces a "more focused learning experience". Later, because of "the minute video", David Penrose is also called the One Minute Professor, who has laid the foundation for the development of the micro lecture, and also made the micro - curriculum well - known.

\subsection{Current situation of domestic research:}

Compared with foreign countries, the concept of micro lecture was put forward a little later in our country. It was first proposed by Hu Tiesheng of Foshan Education Bureau. It can be seen that the domestic literature mainly focuses on the concept, characteristics, development and application of micro-lesson, and reports and studies on the combination of theory and practice of "micro lecture" are emerging. There are very few researches on the application of "micro-course" in the teaching of various specialties in colleges and universities. However, the experts and scholars in the domestic filed still agree with the micro teaching mode. And then the research literature is rising in geometric form, and the practical achievements are also emerging in large numbers.

\section{Analyzing three teaching modes:}

\subsection{The comparison of the three concepts:}

MOOC (massive open online courses) is a large open online course. "M" represents Massive (mass); "O" on behalf of the Open (open); "O" represents Online (online); "C" represents Course (course). MOOC not only supports free learning, can provide instructional videos. For many learners get credit or certificate.

Micro course is a kind of new online video course based on micro - teaching video as the main carrier aiming at the knowledge point or teaching link of a certain subject, and supporting a variety of learning modes. The core composition of "micro-class" is classroom teaching video, and it also contains material courseware, practice test, student feedback, teacher evaluation and other auxiliary teaching resources related to the subject. 
"Flipped Classroom" or "Inverted Classroom" refers to the readjustment of the time inside and outside the classroom. In this teaching mode, the decision transfer to learn from the teacher to the students. Students are allowed to focus more on active project-based learning in the precious time. Work together to solve the challenges of localization or globalization and other real-world problems to gain a deeper understanding.

\subsection{The characteristics of the three modes:}

The characteristic of MOOC: (1) Curriculum integrates many kinds of digital resources, forming rich curriculum resources and diversified learning ways. (2) Breaking the limit of the number of traditional courses to meet the needs of large scale curriculum learners. (3)Breaking through the limit of traditional time, space, learners all over the world can learn MOOC courses at home and abroad from the internet.(4)MOOC courses have a higher enrollment rate, at the same time, have a higher dropout rate. This requires learners to have a strong self-regulated learning to complete the course on time.

The features of micro course: (1) it can also be called a "lesson fragment" or "micro lesson". The teaching time is very short, usually 5-8 minutes. The longest one is no more than 10 minutes. (2) Although the teaching content of micro course is less, but the gathering problem is highlight to the theme. Further more, the classroom teaching is more streamlined in a subject knowledge (such as teaching focus, difficulties, doubts the content of teaching in the classroom), which reflects a teaching circle ,teaching subject, learning strategies, teaching methods, teaching ideas and so on. (3) it can be heard others to evaluate their teaching behavior, get feedback information. Compared with the traditional class, the teacher will not be nervous in the scene teaching, and lighten the psychological pressure. Listeners don't have to worry about how to evaluate properly. Therefore, they can more objective and normally common on the class.

The feature of flipped classroom:(1) The features of the flipped teaching mode:(1)flipped classroom refers to readjust the in-class or after-school time, and transfer the decision from teachers to students. In this teaching mode, students can focus more on active project-based learning in the precious time, and joint research and problem-solving. So they can obtain a deeper understanding. (2)After class, students can watch the teaching video and grasp their own rhythm. When they understand, they can fast skip. But if they did not move back again to watch, it can also stop while taking notes. It's a relaxing atmosphere; No body cannot keeping up with the teaching pace because of their distractions. And also they don't felt as stressful as learning in class. (3)Flipped classroom has promoted the class interaction in an all-round way. The teacher has become the instructor rather than the transmitter, and also has the opportunity to observe the interaction among the students.

Students have set up their own cooperative learning groups, helping and learning each other, rather than relying on teachers as the only transmitter of knowledge.

They began to realize that teachers have just guide to their learning, but not to command the instructions.

\section{Analyzing micro teaching in college English}

\subsection{The function of micro teaching}

(1)Micro teaching is the effective supplementary in college English teaching. The traditional teaching mood has relied mainly on teacher lecturing while student learning subsidiary. The students always can't keep their excitements in that traditional class, and finally lost their study interesting. The interesting pictures and videos in the Micro teaching can quickly grasp the student's attention, and increase their study interesting. Micro teaching can flexibly apply in each link according to the teaching purpose.

(2)Micro teaching offers the valid learning resource to students' independent study. Learning any language can not be simply depended on the learning just from class. Teachers can resolve the professional knowledge into each single point, and use the short and pithy videos designed by every micro teaching. The platform of students' independent study is provided by the abound resource and intensive points in micro teaching. 
(3)The development of micro teaching is beneficial to improve the teaching level and and selfcritical ability, to promote their professional qualification and master modern information technology. Teachers are going though the progress of "research - practice - reflection - rediscovery - repractice-rethinking" step by step. At the same time, the level and ability of teaching and research has increased constantly.

\subsection{The application of flipping classroom in college English course}

Whenever before, during or after class, students can use micro-lessons on each stage with its specific role. These progress such as self-regulated learning before class, cooperative learning in class, summing up and reflection after class are the core of this teaching mode. Students should learn basic knowledge and complete the autonomous learning task before class, then watch the micro video and digital teaching resources which prepared by teachers.

In this way, it can be shorten the explanation time by the leading and emphasis and difficulties of new class in advance, and then maximize the preparation effect .In order to improve students' mastery of the content, the teacher will answer the feedback questions in class, then analysis and conclude the key and difficult points in the video which are given to the students. This not only saves teachers' time and energy, but also leaves more time for teacher-student interaction and classroom activities. After-class exercising and evaluation, student working display, Mutual evaluation and feedback, corresponding assessment tests.

Flipped teaching mode greatly improves teaching efficiency and activities which compared with the traditional teaching mode. It can abandon the traditional mode "teacher lectures, while student listens" and inspire students' participation and enthusiasm through group discussion, cooperative study and interactive evaluation.

\subsection{Integrate micro course and flip classroom as a whole.}

A large number of teaching videos on the micro course platform, which taking some knowledge point or teaching link as the design object, then present the teaching activities with the wonderful short video, which also provides the resource support for the implement of flipping classroom. The teaching practice shows that students can choose the preview according to the micro lesson video theme. If the topic is novel and interesting, it will greatly increased the students' initiative choice.

The flipped classroom spread in large-scale, which will develop into the main teaching method of intelligent education. Finally it will become an important force to promote the social transformation. Whether it determines the curriculum become the center of the learner, thus mobilizing their enthusiasm to participate in the study is by the various forms.

In this way, we can make more full use of educational resources, improve the quality and efficiency of the class, and guide the teaching of students more effectively. They influence each other, combine with each other and complement each other.

\section{Discussion}

The Problems Existing in College English micro Teaching

(1) How to integrate the development of micro course with the content of classroom teaching?

At present, the learning of micro - curriculum resources can still not replace the traditional class learning. In the future, the development of micro courses should be integrated with the contents of classroom teaching, then gradually forming topical and curricula, so as to assist classroom learning and autonomous learning effectively.

(2) If the development of micro - class match with the student's language learning need?

At present, the development of the micro course is mainly used to improve the professional quality and the professional ability. But by no means, developing the micro - curriculum resources from the angle of the student's demand, which is very harmful to the development of the micro - class.

(3) How should college English teachers adapt to the reform of "Internet+ English education"?

Students can choose their teachers by themselves. Unique and innovative teaching will gain in popularity, and the entirely rigid way will be eliminated. For teachers, this is no doubt huge pressure. Although many challenges will be encountered in this new situation, it is more important to promote the teachers' creative ability. College teachers should not only make a breakthrough in scientific 
research, but also have the innovation in the course teaching. Only constantly groping, integrating resources, adding innovative points to the curriculum, so as to create their own teaching characteristics.

\section{Conclusion}

The essence of MOOC teaching is the teachers teaching in the classroom, with video, documents and other forms on the web, for more people to provide learning opportunities on the. MOOC platform a lot of teaching video, also provides support for the implementation of resources. In the course of micro flipping a knowledge point or teaching as a design object the presentation of teaching activities with a short video, usually used for flipping the classroom resources. And the implementation of a wide range of flipping the classroom, it will become the main teaching methods of intelligent education, it will become an important force for social change. It can make full use of educational resources, can improve the quality and efficiency of classroom, and guide more effective the students' teaching. Among the three mutual influence, mutual combination, complement each other.

Of course, many scholars have also pointed out that the shortage of MOOC. The most outstanding problem is the lowest completion rate which is directly caused by lack of face - to - face communication, incomplete learning experience and difficult assessment of learning effect. The high requirements for studying MOOC is relative to the learner's autonomous learning ability. However, the self-regulated learning of the majority learners is not ideal, which will inevitably affect the MOOC course learning. So, online learning based on Mooc can not completely replace the traditional classroom teaching. It also needs teachers' supervision and guidance, face-to-face communication and interaction between teachers and students to make up for its deficiency under the flipped classroom mode. Therefore, how to mix and innovate the traditional classroom and MOOC together? In order to improve the quality of teaching, and to develop the effect of the course, to achieve the sustainable development, which is a great topic for educators to discuss and practice together.

\section{Acknowledgments}

Fund Project: "Research and Application of the Teaching Mode of College English Micro Course" (No. 2016-JYJG-QN002)

\section{References}

[1] Morris L V. Little Lectures. Innovative Higher Education,2009,34( 2) : 67 -68.

[2] Berrett,Dan. How'Flipping'the Classroom Can Improve the Traditional Lecture. The Education Digest,2012.

[3] Kathleen F. Upside Down and Inside Out: Flip Your Classroom to Improve Student Learning. Learning and Leading with Technology,2012( 6) .

[4] Armando Fox,David Patterson. Software Engineering Cur-riculum Technology Transfer: Lessons Learned from Ebooks,MOOCs, and SPOCs. SPLASH Education Sympo-sium, 2013-1028, Indianapolis, USA.

[5] Brown M. Moving into the post-MOOC era [OL]. <http://www.educause.edu/blogs /mbbrown /moving-post-mooc-era.>

[6] $\mathrm{Hu}$ Tisheng. Micro-course: a new trend in the development of regional education information resources \&bra; J \&ket;. Electrochemistry Education Research, 2011 (10) : 61 - 65 .

[7] [6] Xia Zhongwen. Applied research and Reflection on the use of micro courses to promote subject teaching[J]. China information technology education, 2012 (11): 13 -14.

[8] Hu Cai-li, Ma Ying-ying. Feasibility Analysis of the Application of flipping classroom Teaching Model in Chinese Colleges and Universities[J].Software introduction: 2013 (7).

[9] Lu Haiyan. Feasibility Analysis of the Application of "flipping classroom" Model based on Microcourse in College English Teaching [J] A Foreign language Audio-Visual Teaching [J] / 2014 (4): 33-36. 
[10]Zhang Qian, Jiang Xue. Reflection on the Application of Microteaching in the Information Age to College English Teaching ; Out - of - school education in China , 2014, ( 9 ) : 106 - 107 .

[11][Liu Liu Z, Wang Dan. Review on the Research and practice of flipping classroom at Home and abroad. $[\mathrm{J}]$.Contemporary educational theory and practice.

[12]Kang Yiqin. Analysis of MOOC in online Education [J] .Educational Research of Tsinghua University, China (in Chinese): 85-93 (1).

[13] The characteristics of Li Manli. MOOC and the principle of teaching design [J]. Education Research of Tsinghua University, 2013 (8)

[14] The Cold thinking on the Hot of Highlands. MOOC--Reflections on the six problems of MOOCs Teaching in the World. [J] .Journal of distance Education: 39-47.

[15] Hu Tiesheng, Huang Mingyan, Li Min, the three stages of the development of micro class in China and Its Enlightenment [J]. Distance education magazine, 2013 (4): 36-41.

[16] A study of College English assisted teaching mode in Gu Shimin's virtual learning environment- an integrated framework of cooperative learning and autonomous learning to explore[J]. Foreign language audio-visual instruction, 2011, (6): 59-65. 